

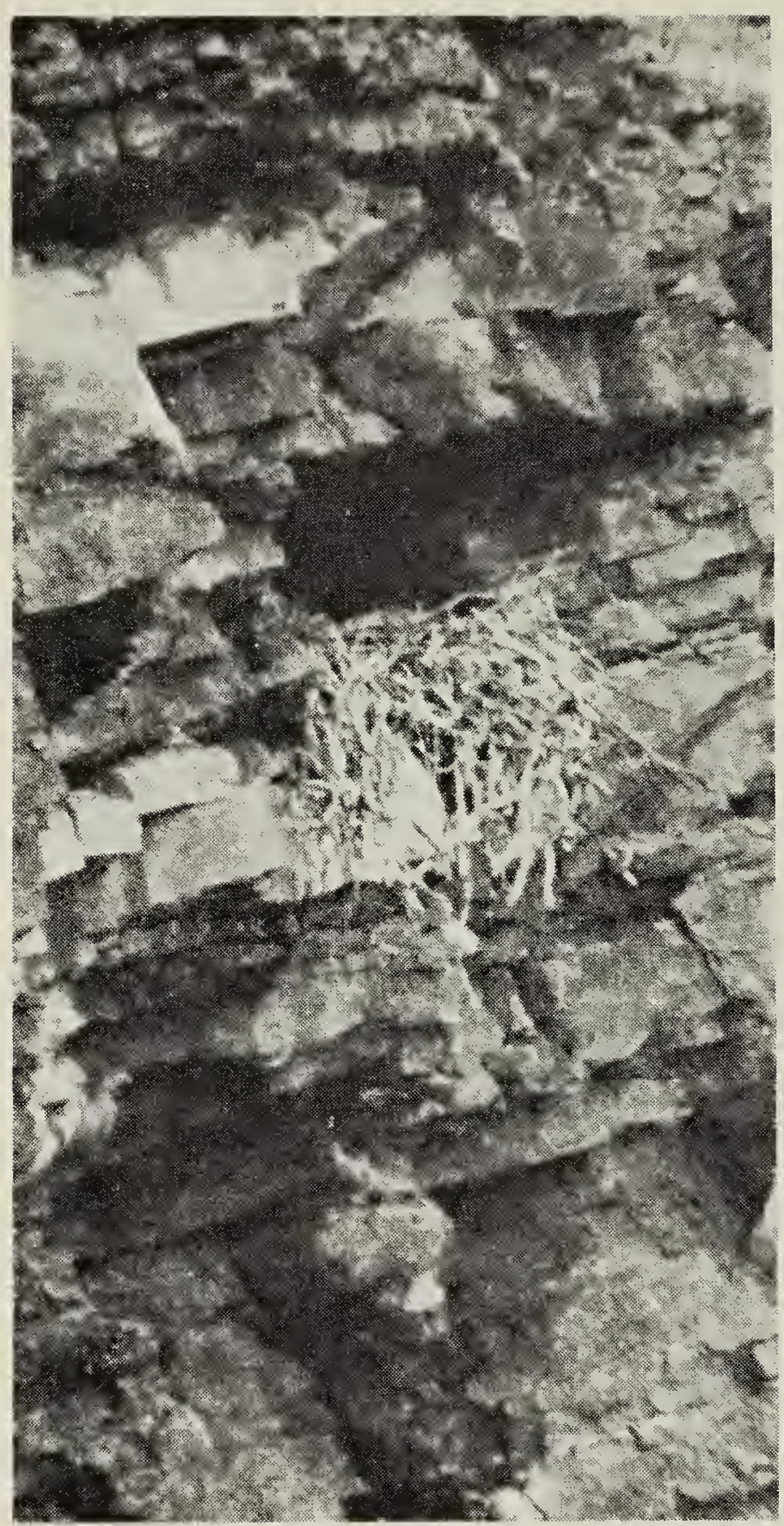

Common Raven nest site

the nest or parents were seen. The extremely keen-sighted adult at the nest (perhaps the female) detected my approach and flew to a nearby tree voicing its concern. Soon the other adult arrived and for $30 \mathrm{~min}$ utes both birds either soared on horizontal wings over the area or sat on prominent trees uttering harsh "crawks" after which their excitement waned and they left. The young until now had huddled in the nest but with the threat "gone" they became curious. They exercised their wings or merely watched my movements which, if too noisy or quick, sent them scrambling to the back of the nest and halted any vocal encouragement they had been giving me.
Personnel from the R. B. Miller Biological Station later established that there were five young in the nest. One young taken from this nest proved to be a very clever though mischievous pet. In August it was found dead, apparently shot. Through shooting and indiscriminate poisoning, many ravens die, even though their scavenging habits make they decidedly useful to man. One individual that I watched flying low along a forestry road one morning seemed so preoccupied with searching for food, perhaps roadkilled animals, that it did not veer away until it was within 100 feet of us.

Ravens seem to have increased in numbers in Alberta's "Rockies" during the past 10 years. Young ravens recently out of the nest have been observed in this southwest portion of Alberta by competent observers (Salt and Wilk, 1966. Birds of Alberta) but, to my knowledge, this constitutes the first record of ravens nesting in that area.

\section{THIRD RECORD OF SCISSOR-TAILED FLYCATCHER IN ALBERTA}

by Spencer G. Sealy

Department of Zoology, University of British Columbia, Vancouver

On June 22, 1964 I observed a Scissor-tailed Flycatcher (Muscivora forficata) on a telephone wire near the South Saskatchewan River, about 10 miles north of Bow Island, Alberta. It was seen hawking insects on several occasions.

There are two previous records of this species from Alberta, one seen at Claresholm on August 20, 1943 and a second observed at Fort Chipewyan on June 17, 1952 (Salt and Wilk, 1966, Birds of Alberta).

This observation was made while I was employed with the Alberta Department of Lands and Forests, Fish and Wildlife Division, in the summer of 1964 . 